\title{
A Review and Parametric Investigation Into Nanofluid Viscosity Models
}

\author{
Paul N. Nwosu ${ }^{1}$ \\ Department of Mechanical Engineering Science, University of Johannesburg, P.0. Box 524, Auckland Park 2006, South Africa \\ e-mail: pauln@uj.ac.za \\ Josua Meyer \\ Department of Mechanical and Aeronautical Engineering, University of Pretoria, Private Bag X20, Hatfield 0028, South Africa \\ Mohsen Sharifpur \\ Department of Mechanical and Aeronautical Engineering, University of Pretoria, Private Bag X20, Hatfield 0028, South Africa
}

\begin{abstract}
The degree of variability between theoretical and empirical nanofluid viscosity model predictions and relevant experimental data is examined in this work. Results confirm a high degree of variability in the compared data; with some observed inconsistencies in the model formulations and the predicted data, consequently, a range of constitutive fac-tors need to be incorporated into the models in order to accurately predict the rheologi-cal behavior of nanofluids in different use conditions. Notably, conducting broad theoretical studies and empirical investigations into the rheological behavior of nano-fluids incorporating the fundamental parametric variables can plausibly lead to near-generalized models.
\end{abstract}

Keywords: nanofluid, viscosity, models, parameters

\section{Introduction}

Potentially, nanofluids can improve the thermal performance and efficiency of energetic processes. However, some limitations which include anomalous viscous behavior $[1,2]$, tendency to clog flow channels as well as instability $[3,4]$ have particularly raised a number of concerns in the heat transfer performance. Nanofluids are fluids which contain solid particles measuring between 1 and $100 \mathrm{~nm}$. The rheological and flow behavior of nanofluids is an important consideration in the application of nanofluids as heat transfer fluids.

Significant improvements in the viscous and thermal performance of nanofluids have been reported [1-3]. Krieger and Dougherty [4] postulated a mechanism to account for non-Newtonian flow behavior in a suspension of rigid spheres, based on the intrinsic viscosity and volumetric fraction. Similarly, Keblinski et al. [5] reported an anomalous behavior in the viscosity of nanofluids, and concluded that thermal properties of nanofluids can be linked to the ballistic nature of nanoparticles, combined with direct or fluidmediated clustering effects. Nguyen et al. [6] noted the existence of critical temperatures beyond which the hysteresis phenomenon occurs in $\mathrm{Al}_{2} \mathrm{O}_{3} / \mathrm{H}_{2} \mathrm{O}$ nanofluids. Early studies by Choi and Eastman [7] into $\mathrm{Cu} / \mathrm{H}_{2} \mathrm{O}$ nanofluids posited that nanofluids were ideal heat transfer fluids with no appreciable increase in pumping power. Recent studies however have shown that while some nanofluids exhibit the Newtonian behavior in certain ranges of shear rate, some are intrinsically non-Newtonian [8]. Further examination of literature $[8,9]$ shows that base fluids with low viscosity are more likely to exhibit the non-Newtonian behavior; in addition, particle shape also influences strongly the shear-dependent behavior for highly concentrated suspensions [8]. Importantly, empirical investigations into the viscosity of nanofluids have shown that existing theories, models, and correlations are limited. Notably, many of the existing formulas are based on Einstein pioneering work $[2,6]$ due to the fact that they only relate viscosity to the volume fraction, and tackle partially the influence of base fluid and nanoparticle properties, as well as the mechanism of solid-liquid interaction on viscosity.

Parameters which have so far been used in characterizing the rheological behavior of nanofluids include [6,8-10]: volume fraction/concentration, temperature, packing fraction, thickness of

\footnotetext{
${ }^{1}$ Corresponding author.
}

the nanolayer, particle shape/aspect ratio, aggregate radius, interparticle spacing, and the capping layer. Where there is good agreement between empirical data and model results, the general trend is to constrain the models to such parameters. Despite good agreement between experimental data and some theoretical results, a wide range of constitutive factors need to be included in modeling the rheological behavior of nanofluids, generally [4,11-13]. Also, there are several models based on mechanisms such as the kinetic gas [12], local composition [14], Brownian motion [15], two-fluid (i.e., binary mixing) [16], and effective medium [17] theories; however, when they are applied to model the effective viscosity there are inconsistencies in the obtained results. Where such models are applied in conditions which differ from those in which they were obtained, there is a tendency to obtain different results. It cannot be said, therefore, that the existing models are particularly adequate. Agglomeration of nanoparticles and some unexplained phenomena have also made the formulation of a generalized model a challenge, emphasizing the need for more accurate models.

In this paper, therefore, results of empirical and theoretical models which are used to predict the viscosity of nanofluids are investigated, as well as the effects of the parametric variables on the viscosity. This becomes necessary due to the present interest directed toward developing models which only address the effects of the viscosity parameters and viscous behavior in a restricted sense. Consequently, suggestions for developing more accurate models are made with particular concern to specific nanofluid systems, so as to broaden the applicability of the models in various use conditions given that most of the models have limited use in real world applications beyond those of the constrained experimental environment.

\section{Empirical Rheological Investigations}

2.1 Newtonian and Non-Newtonian Behavior. The potential application of nanofluids in engineering systems [18,19] depends to a large extent on their viscosity relative to those of pure fluids. There are several empirical investigations into the viscosity of nanofluids. The phenomenon of shear thinning has been widely reported by different researchers who investigated this behavior for different nanofluids with varying compositions of nanoparticles. Yu et al. [20] conducted an experimental investigation into the viscosity of aluminum nitride nanofluids. Aluminum nitride nanoparticles (AINs) were dispersed in ethylene glycol (EG) and propylene glycol (PG) base fluids. For a volume concentration less than $5.0 \%$, both fluids exhibited Newtonian 
behavior, while for a volume concentration greater than $5.0 \%$, there was an obvious shear-thinning behavior in the reported data. The results indicated that the AIN/EG nanofluid exhibited the shear thinning behavior at any constant fluid temperature depending on volume fraction. The lower the temperature the more obvious this behavior occurred. Similar trends were observed for the AIN/PG nanofluid, the critical volume for the rheological transition was $\phi=5 \%$. Although this study obtained the threshold for the transition, it was limited to a narrow range of volume fraction and temperature influence; hence, there is need for further investigation into the effects of a broadervange of volume fractions, temperature, and base fluid density effects.

The empirical study by Prasher et al. [21] indicated that the viscosity $\mathrm{Al}_{2} \mathrm{O}_{3} / \mathrm{PG}$ nanofluids was independent of shear rate, and increased with volume fractions. Effects of increasing volume fraction on the relative viscosity have been attributed to agglomeration [6,14]. Nonetheless, this relationship is not well-understood, more studies are needed to understand the underlying mechanism.

Chen et al. [15] studied the rheological behavior of EG-titanate (TNT) nanotube nanofluids. (The SEM image of the nanoparticles is shown in Fig. 1.) They reported a shear-thinning behavior for the nanofluid, which was attributed to interparticle structuring effects. It was also noted that the viscosity of the nanofluid was influenced by temperature and shear rate. This was in agreement with studies by Pastoriza-Gallego et al. [22]. The viscositytemperature dependence was attributed to Brownian diffusion and convection effects. The empirical results agreed well with the modified Krieger-Dougherty (K-D) equation [4], when $a_{a} / a=9.46$.

An experimental investigation into the shear and longitudinal viscosities of dilute suspensions of $\mathrm{Al}_{2} \mathrm{O}_{3}$ in decane and polyalphaolefin (PAO) was undertaken by Schmidt et al. [17]. An optical technique was used to measure the longitudinal viscosity at frequencies ranging from 200 to $600 \mathrm{MHz}$. The obtained results indicated that there was no formation of nanoparticle clusters in decane-based nanofluids. The alumina particles in decane and PAO base fluids exhibited shear viscosity. The results also indicated that there was no sedimentation of the dilute concentration of $\mathrm{Al}_{2} \mathrm{O}_{3}$ nanoparticles in decane. The obtained results were, however, in conflict with the effective medium theory [17], but agreed well with models based on Brownian dynamics [15]. It is instructive to note that models based on Brownian motion can hardly explain observed behavior. In addition, the inability of the decane-based nanofluids to form clusters could be useful in explaining the effects of base fluid densities on nanoparticle aggregation and viscosity.

Venerus et al. [9] conducted viscosity measurements into some nanofluids, as part of the International Nanofluid Property Benchmark Exercise (INPBE). The INPBE sought to streamline differences in nanofluid viscosity measurements. Data were reported for seven different nanofluids, composed of dispersions of metal-

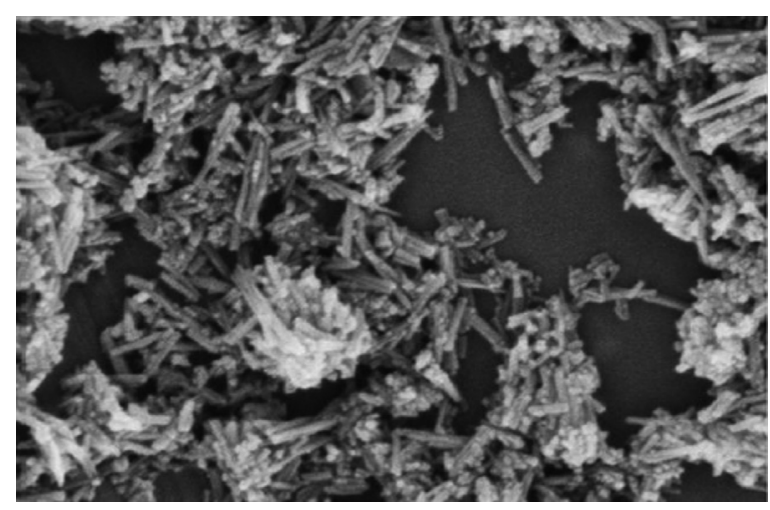

Fig. 1 SEM image of TNT nanotubes with visible agglomeration, Chen et al. [15] oxide nanoparticles in water and synthetic oil. Ten (10) laboratories in different parts of the world were part of this benchmarking exercise, which sought to examine the influence of particle shape and concentration on the viscosity of nanofluids. The criteria for overall effectiveness of nanofluids as heat transfer fluids were proposed in the work $[21,23]$. Results showed that of the seven nanofluids studied, two exhibited a shear-thinning behavior, while the remaining five the Newtonian behavior. For nanofluids with both spherical and rod-shaped nanoparticles, the dependence of relative viscosity on particle concentration (volume fraction) was significantly stronger than predicted by dilute suspension theory. This discrepancy was attributed to particle agglomeration. The nanofluids considered in the study, however, failed to meet the criteria for heat transfer application as given by Prasher et al. [21] and Garg et al. [23], which state that for a nanofluid to be suitable for a heat transfer application, the absolute value of intrinsic nanofluid viscosity $\eta$ should be 4-5 times smaller than the effective thermal conductivity of the nanofluid $k$. Despite this study being far-reaching, it failed to examine the effects of polarity of the base fluid, density, dispersion energy, and settling on the viscosity.

2.2 Effects of Temperature. Effects of varying temperature on the effective viscosity of nanofluids have been widely reported. Tavman et al. [24] conducted an experimental investigation to examine temperature effects on the viscosity of $\mathrm{SiO}_{2} / \mathrm{H}_{2} \mathrm{O}$ and $\mathrm{Al}_{2} \mathrm{O}_{3} / \mathrm{H}_{2} \mathrm{O}$ nanofluids with different particle concentrations of alumina and silica. The effective viscosity of the nanofluids was seen to increase with particle concentrations, and decrease with increasing temperatures. The Einstein model applied in Ref. [25] was used to predict the viscosity trend of the nanofluids; however, it underpredicted the empirical data, hence the need for accurate models which incorporate a wide range of parameters.

Similarly, Chen et al. [15] reported that the viscosity of EG/ TNT nanofluid was influenced by temperature. The study focused mainly on a limited range of temperature; as a result, a comprehensive characterization of high temperature effects on the viscosity is essential in future investigations.

Pastoriza-Gallego et al. [22] studied the influence of particle size and polydisperity on the viscosity of $\mathrm{CuO} / \mathrm{H}_{2} \mathrm{O}$ nanofluids. Two different samples of $\mathrm{CuO} / \mathrm{H}_{2} \mathrm{O}$ nanofluids were considered in the work, with the following particle sizes: $D=33 \pm 13 \mathrm{~nm}$ $\left(\mathrm{S}_{1}\right)$ and $D=11 \pm 3\left(\mathrm{~S}_{2}\right)$. The empirical investigation led to the following hypothesis: (i) that the colloidal dispersions might be non-Newtonian below a certain temperature or particle size, suggesting the need for rigorous rheological analysis and (ii) simplified viscosity theories might be insufficient to describe the complex behavior of the nanofluids, hence other effects such as interparticle interaction, solid-fluid interaction, friction, and particle anisotropy should be factored in nanofluid viscosity theories.

Nguyen et al. [6] reported a strong dependence of viscosity on temperature for $\mathrm{Al}_{2} \mathrm{O}_{3} / \mathrm{H}_{2} \mathrm{O}$ nanofluid. An increase in temperature of the nanofluid was noted to have a weakening effect on the interparticle/intermolecule forces. It was reported that the slope of viscosity-temperature plot was pronounced in the range of $22-40{ }^{\circ} \mathrm{C}$, and the gradient was seen to increase with volume fractions. For high volume fractions, however, they could not provide a correlation that could simultaneously take into account temperature, particle concentration, and size effects on the relative viscosity. Also, the temperature range was limited to values less than $100{ }^{\circ} \mathrm{C}$, hence the obtained models may not be applicable to higher temperature conditions.

Dzido et al. [2] conducted an experiment into $\mathrm{CuO} / \mathrm{H}_{2} \mathrm{O}$ and $\mathrm{CuO} / \mathrm{EG}$ nanofluids, with volume fractions of $1.5 \%$ and $2.5 \%$ of $\mathrm{CuO}$, respectively. Relative viscosity measurements were taken in temperatures ranging from 25 to $65^{\circ} \mathrm{C}$ and share velocities of 20 to $200(1 / \mathrm{s})$. The following stabilizing agents were used:

- Triammoniumcitrate

- Cetyltrimethylammonium bromide 
The results obtained from the investigation gave a nonlinear, non-Newtonian behavior for plots of shear stress versus shear rate, and the effects of temperature on the viscosity were considerable. The Klein's model [2] was used to model the influence of shear rate (shear velocity) and temperature on the viscosity for the reported results. Plots of measured and calculated values of the effective viscosity gave good agreement for the model. The error margin was between $+10 \%$ and $-10 \%$. The obtained results indicated that the model due to Klein [2] can be employed in characterizing the nanofluids; however, the model is not generalized. The empirical investigation principally emphasized temperature and shear rate effects on viscosity; however, the effects of flow conditions, temperature, particle shape, and size on viscosity were not investigated.

Namburu et al. [26] presented empirical results on the effects of temperature on viscosity of ethylene/glycol (EG) and $\mathrm{H}_{2} \mathrm{O}$ nanofluids with copper oxide nanoparticles. The following range of temperature was considered in the study: $-35^{\circ} \mathrm{C}-50^{\circ} \mathrm{C}$, in order to show the applicability of nanofluids in extreme cold conditions. The results showed that nanofluids can be used in extreme cold conditions. The thrust of future research should be directed toward the usability of nanofluids in systems subject to widely varying thermal conditions so as to identify thermally stable nanofluids for use as high performance heat transfer fluids.

2.3 High Shear Viscosity. The basis of the present investigation into high shear viscosity lies in the fact that high shear viscosity is desirable in practical applications of nanofluids. The shear viscosity of non-Newtonian fluids approaches a constant value at high shear rates and this is actually relevant to real-life applications of nanofluids where the fluids are subject to vigorous motion and susceptible to very high shear velocities. High shear viscosity in nanofluids has been reported $[8,17]$. The following factors characterize high shear viscosity [8]:

- The presence of nanoparticles in nanofluids; high shear viscosity appears to be more likely in nanofluids containing rodlike particles than in those containing spherical manner.

- High shear viscosity increases with increasing nanoparticle fraction in a nonlinear fashion.

- Regression of high shear viscosity can be given as a binomial relationship

$$
\eta=\eta_{0}\left(1+10 \phi+(10 \phi)^{2}\right)
$$

where $\eta$ and $\eta_{0}$ are shear viscosities of nanofluid and base fluid, respectively.

Chen et al. [27] investigated the heat transfer and flow behavior of aqueous TNT nanotube nanofluids. These fluids were found to be non-Newtonian. The shear viscosity of the nanofluids approached a constant value at shear rates higher than about $(1 / \mathrm{s})$ depending on the nanoparticle concentration. This behavior was found to be higher than predicted by conventional models for dilute suspensions. The nanotubes were observed to be prone to entanglement and agglomeration in comparison with spherical nanoparticles.

Zhou et al. [28] studied the effects of shear rate and temperature on viscosity of alumina PAOs nanofluids. The Newtonian behavior was observed for the base fluid. With addition of alumina nanospheres and nanorods $(\phi<3 \%)$, the nanofluids initially exhibited Newtonian behavior and with further addition of these particles, the fluids transitioned to a non-Newtonian behavior, which was seen to be independent of temperature. The reported results can be summarized as follows:

- Dynamic viscosity of the nanofluids is dependent on temperature; as temperature increases the dynamic viscosity decreases. This has also been reported by various researchers $[6,29]$.
- The relative viscosity of the nanofluid is independent of temperature at low volume concentrations, and can be predicted by the Vogel-Fulcher-Tammann equation [29].

$$
\eta(T)=A \exp \left(B / T+T_{0}\right)
$$

where $A, B$, and $T_{0}$ are empirical parameters. Further research is needed to determine the temperature-dependent transition relative viscosity for useful practical applications.

2.4 Hysteresis. The phenomenon of hysteresis in nanofluids was first observed by Nguyen et al. [6]. The experimental investigation into $\mathrm{Al}_{2} \mathrm{O}_{3 /} \mathrm{H}_{2} \mathrm{O}$ nanofluid indicated an increase in the dynamic viscosity with particle volume concentrations, and a decrease with increasing temperatures. It was observed in the work that the temperature level to which the nanofluid was heated up had a significant influence on the viscous behavior and suspension properties of the nanofluid. Some irreversible damages to the suspension properties of the nanofluid were observed, this became obvious beyond a critical temperature $T_{\mathrm{cr}}$, and resulted in a rather erratic increase in the nanofluid viscosity. The $T_{\mathrm{cr}}$ values were dependent on the particle size and volume fraction. More rigorous studies will be of essence to understand this phenomenon especially in operating conditions beyond those tested in Ref. [6]. Retrospectively, the hysteresis phenomenon can perhaps be explained by an earlier work by Paul and Cotts [30] on the effects of aggregation and solvent quality on the viscosity of semidilute suspensions. As noted in the work [30], the theoretical explanation for this could be linked to the presence of supramolecular structures or aggregates. The impact and extent of aggregation on the semidilute suspension [30] was minimal upon heating but increased slowly when cooled as observed also by Nguyen et al. [6]. Aggregation effects increased with volume fraction [6], and can manifest as hysteresis in plots of $\eta_{\mathrm{nf}}$ versus $T$. Although the work of Paul and Cotts [30] and Nguyen et al. [6] differ with respect to the suspended particle sizes and base fluids, they give a clue as to the effects of aggregate formation and reformations upon an external influence. The extent of hysteresis in both studies was seen to be influenced by increasing volume fractions and concentrations. The work of Paul and Cotts [30] suggested that the solvent composition affected the hysteresis dependence of viscosity on temperature. A generalized model could well be extended to nanofluid systems on the basis of the analogous studies.

2.5 Effects of Particle Size, Shape, and Volume Fractions. Studies which examined the interdependence between nanoparticle size, shape, and volume of fractions have been undertaken in recent works. Chandrasekar et al. [31] conducted an experimental investigation as well as a theoretical study of the viscosity of $\mathrm{Al}_{2} \mathrm{O}_{3}$ /water nanofluid with the conclusion that viscosity of the nanofluid was strongly influenced by volume fraction. The $\mathrm{Al}_{2} \mathrm{O}_{3} /$ water nanofluid used which was used in the study had a particle size of $43 \mathrm{~nm}$, and a range of volume concentrations of $0.33-5 \%$ was considered. This has been widely reported [6].

Relatively, Murshed et al. [32] conducted an experimental investigation into the relative viscosity of $\mathrm{T}_{1} \mathrm{O}_{2} / \mathrm{H}_{2} \mathrm{O}$ and $\mathrm{Al}_{2} \mathrm{O}_{3}$ / $\mathrm{H}_{2} \mathrm{O}$, reporting an increase in viscosity with volume concentrations, respectively. The experimental investigation was limited in that it considered only two nanofluids, and did not investigate the effects of particle size, aggregation, and volume factions.

Tsai et al. [33] studied the effects of viscosity of base fluids on thermal conductivity of nanofluids. The study was instrumental in understanding the interdependence of the thermal conductivity and viscosity. A crucial theoretical postulation was that nanofluids are expected to show an increase in thermal conductivity without an increase in pressure drop, which was linked to the effective viscosity. In the study, $\mathrm{Fe}_{3} \mathrm{O}_{4}$ nanoparticles were suspended in base 
fluids composed of diesel oil and polydimethylsiloxane. The viscosities of both fluids increased with volumetric fraction. The results indicated that the increase in the effective viscosity of the nanofluids did not explicitly affect their thermal conductivities. The study thus concluded that Brownian dynamics was an important mechanism in modeling the effective viscosity.

Pastoriza-Gallego et al. [22] studied the effects of particle size on viscosity considering $\mathrm{CuO} / \mathrm{H}_{2} \mathrm{O}$ nanofluids. The influence of particle size and size distribution on viscosity was negligible. Also, the viscosity of the nanofluid increased with decreasing particle size in low temperatures, following the expected classical behavior for dispersions. The increase in the relative viscosity with volume concentration as observed in the work did not follow the classical trend. This could be as a result of the limited empirical conditions, since a wide variety of parameters were not considered hence an exhaustive rheological characterization is necessary to understand the effects.

Stable aqueous $\mathrm{TiO}_{2}$ nanofluids with different particle sizes and concentrations were studied by He et al. [34] for their (static) thermal conductivity and rheological behavior. The rheological measurements showed that the shear viscosity of nanofluids decreased with increasing shear rate initially, and then approached a constant at a shear rate greater than $100(1 / \mathrm{s})$. Also the viscosity increased with increasing particle (agglomerate) sizes and particle concentration. The results also showed that the pressure drop of the nanofluid was very close to that of the base liquid for a given Reynolds number. More work is required to validate various postulations on the effects of particle size on pressure drop at relatively high Reynolds numbers.

Chen et al. [15] demonstrated that nanofluids containing rodlike particles exhibited a much stronger shear-thinning behavior in comparison with those containing spherical nanoparticles, and that the viscosity of nanofluids can be predicted by the K-D models [15], if the volume concentration of the particles were replaced with the volume concentration of the nanoparticle aggregates. For spherical nanoparticles, it was determined that an aggregate size of approximately three times $(3 \times)$ the primary nanoparticle size gave the best prediction for the model. Practically, it is difficult to estimate the size of aggregates; thus, a generalized model will be of important benefit.

Putnam et al. [35] observed that there are numerous competing theoretical and empirical models. Importantly, there still remains a void in the study/characterization of the rheological behavior of nanofluids due to the fact that experimental investigation currently lags behind theoretical modeling, hence there is a need to employ functional mechanisms which could account for aggregation; particle or aggregate size distribution; particle and aggregate shapes; solvent quality; density and polarity; so as to provide a broader theoretical foundation for the study of the viscous behavior of nanofluids.

2.6 Rod-Like Particles. Chen et al. [15] reported that in a quiescent state, a rod-like particle can have the following types of motions: the Brownian diffusion (i.e., rotational motion about the midpoint) and translational motion. For dilute suspensions with a number density between 0 and $1 / L^{3}$ or a volume fraction between 0 and $1 / p^{2}$ (where $L$ is the length of the particle, $c$ is the number of rods per unit volume, and $p$ is the concentration of the particles), Chen et al. [15] noted that the average spacing between the particle would be much largest than the biggest dimension of the rod. In this case, the Brownian motion is determined by the viscosity of the base fluid and the viscosity of the suspension at zero shear rate $\eta(0)$, given by [15]

$$
\eta(0)=\eta_{\mathrm{o}}\left(1+A \cdot c L^{3}\right)
$$

where $\eta_{\mathrm{o}}$ is the viscosity of the base fluid and $A$ is a numerical constant. For suspensions with $1 / L^{3}<c<1 / b L^{2}\left(1 / p^{2}<\phi\right.$ $<1 / p)$, the rotational and transitional motions perpendicular to the rod's axis are restricted. The viscosity values for such nanofluids can be expressed by [15]

$$
\eta(0) \approx \eta_{\mathrm{o}}\left(1+\left(B c L^{3}\right)^{3}\right)
$$

where $B$ is a numerical constant. Nanofluids with nanoparticles in this range are said to be semiconcentrated. Importantly, particle shapes have been widely reported to be of influence in nanofluid viscosity values [22-24,26]; further governing studies are, however, needed to establish a definitive relationship between viscosity and nanoparticle shape.

Avsec and Oblak [12] compared the results of the ward and renewed ward (RW) models, and experimental data for two different nanofluids: (i) $\mathrm{H}_{2} \mathrm{O} / \mathrm{TiO}_{2}$ (with a particle size of $27 \mathrm{~nm}$ ) and (ii) $\mathrm{H}_{2} \mathrm{O} / \mathrm{Al}_{2} \mathrm{O}_{3}$ (with a particle size of $13 \mathrm{~nm}$ ). The $\mathrm{RW}$ model [12] agreed well with the experimental results in predicting the relative viscosity however the volume concentration was only limited to 0.1 , and only two nanofluids were considered. The following factors led to anomalous enhancement of viscosity [12]:

- The motion of nanoparticles;

- molecular level of layering of the liquid at the liquid-particle interface;

- ballistic phenomenon in nanoparticles; and

- clustering of nanoparticles.

Xie et al. [36] investigated some organic base fluids. The experimental work gave results of enhancement ratios of viscosity of $\mathrm{EG} / \mathrm{Al}_{2} \mathrm{O}_{3}$ suspensions which were smaller than those of waterbased suspensions-showing the influence of the base fluid on viscosity. The study also included an investigation into the dependence of the viscosity on $p \mathrm{H}$ values. The isoelectric point was determined to be 9.2 for alumina nanoparticles. When the $p \mathrm{H}$ deviated from this threshold, the nanoparticles were well dispersed because of large repulsive forces. These repulsive forces decreased as the $p \mathrm{H}$ value approached the isoelectric point, this caused coagulation or aggregation of the nanoparticles. The viscosity of the nanofluid increased with $p \mathrm{H}$ approaching this point. More studies are, however, needed to understand the effects of base fluid polarity and $p \mathrm{H}$ on viscosity of nanofluids.

\section{Experimental and Theoretical Models}

Numerous theoretical investigations have been conducted into the suspension rheology of nanofluids. The fundamental work by Einstein [37] on infinite dilute suspensions of hard spheres based on the rotational motion of the spherical shear particle known as vorticity of the shear field, gave the following relation:

$$
\eta=\eta_{\mathrm{o}}(1+[\eta] \phi)
$$

where $[\eta]$ is the intrinsic viscosity of the suspension which for hard spheres was given as 2.5. The model was valid for $\phi<\sim 0.01$. In contrast to the value given by Einstein [37], Anoop et al. [38] obtained an intrinsic viscosity value of ten for $\mathrm{Al}_{2} \mathrm{O}_{3^{-}}$ based nanofluids, considering $p \mathrm{H}$ and the primary viscous coefficient. Hence more studies are needed to understand the effects of $p \mathrm{H}$ and electrostatic charges on the intrinsic viscosity. Batchelor [25] obtained the following model for the relative viscosity of nanofluids for $\phi>\sim 0.01$ :

$$
\eta_{\mathrm{r}}=\eta / \eta_{o}=1+[\eta] \phi+k_{\mathrm{H}}([\eta] \phi)^{2}
$$

where $k_{\mathrm{H}}$ is the Huggin's coefficient known also as the interaction parameter, this coefficient accounts for interparticle interaction as opposed to hydrodynamic effects [8]. The semi-empirical relation proposed by Krieger and Dougherty [4] for shear viscosity 
covering the full range of particle volume concentrations is expressed by

$$
\eta_{\mathrm{r}}=\eta / \eta_{\mathrm{o}}=\left(1-\phi / \phi_{\mathrm{m}}\right)^{-[\eta] \phi_{\mathrm{m}}}
$$

where $\phi_{\mathrm{m}}$ is the maximum particle volume fraction and $[\eta]$ is the intrinsic viscosity, whose typical value for monodisperse suspensions of hard spheres was given as 2.5 . In practical situations, particles are polydisperse hence this assumption may not be valid for all nanofluids. The modified Krieger-Dougherty equation [8] takes into consideration the packing fraction of aggregates in defining the relative viscosity $\eta_{\mathrm{r}}[8]$

$$
\eta_{\mathrm{r}}=\left(1-\phi_{\mathrm{a}} / \phi_{\mathrm{m}}\right)^{-[\eta] \phi_{\mathrm{m}}}
$$

$\phi_{\mathrm{a}}$ is given by $\phi_{\mathrm{a}}=\phi / \phi_{\mathrm{ma}}$, where $\phi_{\mathrm{ma}}$ is the packing fraction of the aggregates. The viscous behavior was assumed to follow a power law with a constant index, $D$. Consequently, $\phi_{\mathrm{a}}$ was given as $\phi_{\mathrm{a}}=\phi\left(a_{\mathrm{a}} / a\right)^{3-D}$, where $a_{\mathrm{a}} / a$ is the ratio of effective radii of aggregates and primary nanoparticles. Chen et al. [27] obtained the following model for the relative viscosity:

$$
\eta_{\mathrm{r}}=\left(1-\frac{\phi}{0.605}\left(\frac{a_{\mathrm{a}}}{a}\right)^{1.2}\right)^{-1.5125}
$$

where $a_{\mathrm{a}}$ and $a$ represent the average radius of the aggregates and single particles, respectively. The above equation is based on the theory that attributes increasing in viscosity values to the aggregation state of nanoparticles. According to this theory, the aggregation phenomena should be relevant for nanoparticles dispersed in base fluids. The particle size distribution (PSD) was seen to play a role in the viscosity trend. If the PSD is discrete, the overall viscosity of an assemblement of noninteracting monomodal suspensions may be calculated as the product of each independent viscosity $[39,40]$

$$
\eta_{\mathrm{r}}=\prod_{i=1}^{m} \eta_{\mathrm{r}}\left(\phi_{i}\right)
$$

where $m$ denotes the number of classes of different average particle sizes considered in the distributions, and $\phi_{i}$ is the corresponding particle fraction. Also, the viscosity of each monomodal suspension can be related to $\phi_{\mathrm{m}}[41]$

$$
\eta_{\mathrm{r}}\left(\phi_{i}\right)=\left[1-\frac{R \phi_{i}}{1-\phi_{i} / \phi_{\mathrm{m}}}\right]^{3.3 \phi_{\mathrm{m}}}
$$

in which $R$ is an adjustable parameter. For a polydisperse mixture of spherical particles, the procedure given by Frankel and Acrivos [42] and Graham [43] can be used to determine $\phi_{\mathrm{m}}$ from the minimum value of $P_{i}$

$$
\phi_{\mathrm{m}}=\min \left(P_{i}\right)
$$

where $P_{i}$ is the packing fraction of each class size $i$ calculated as

$$
P_{i}=\sum_{j=1}^{n} \phi_{i j} \nu_{j}
$$

$\phi_{i j}$ is the volume fraction and $\nu_{j}$ is the binary packing coefficient. The procedures for calculating these two quantities are detailed in Refs. [40] and [44]. Brinkman [45] obtained the following model for predicting the relative viscosity of nanofluids:

$$
\eta_{\mathrm{r}}=\frac{\eta_{\mathrm{nf}}}{\eta_{\mathrm{bf}}}=\frac{1}{(1-\phi)^{2.5}}
$$

where $\eta_{\mathrm{nf}}$ is the dynamic viscosity of the suspension and $\eta_{\mathrm{bf}}$ is the viscosity of the base fluid. Frankel and Acrivos [42] obtained the following model for the relative viscosity:

$$
\eta_{\mathrm{r}}=\frac{9}{8}\left[\frac{\left(\phi / \phi_{\mathrm{m}}\right)^{\frac{1}{3}}}{1-\left(\phi / \phi_{\mathrm{m}}\right)^{\frac{1}{3}}}\right]
$$

The parameter $\phi_{\mathrm{m}}$ was empirically determined. Lundgren [46] proposed a Taylor series-based model for calculating the relative viscosity of nanofluids

$$
\eta_{\mathrm{r}}=\left[1+2.5 \phi+\frac{25}{4} \cdot \phi^{2}\right]
$$

If the second (or higher) order(s) of $\phi$ is neglected in the model, the model simplifies to the Einstein's equation [47]

$$
\eta_{\mathrm{r}}=1+2.5 \phi
$$

The generalized form of Lundgren model [46] was proposed by Graham [43], this accorded well with the Einstein model [37] for low values of $\phi$

$$
\eta_{\mathrm{r}}=1+2.5 \phi+4.5\left[\frac{1}{\left(h_{i} / d_{\mathrm{p}}\right) \cdot\left(2+h_{i} / d_{\mathrm{p}}\right) \cdot\left(1+h_{i} / d_{\mathrm{p}}\right)^{2}}\right]
$$

where $d_{\mathrm{p}}$ and $h_{i}$, respectively, are nanoparticle diameter and interparticle spacing (shown schematically in Fig. 2). The basic premise underlying the above formulas is the linear fluid theory. The linear fluid theory is not valid for all nanofluids, however.

Nguyen et al. [6] proposed the following empirical models for $\mathrm{Al}_{2} \mathrm{O}_{3} / \mathrm{H}_{2} \mathrm{O}$ nanofluid with different particles sizes, 47 and $36 \mathrm{~nm}$, respectively:

and

$$
\eta_{\mathrm{r}}=0.904 e^{0.1483 \phi}
$$

$$
\eta_{\mathrm{r}}=1+0.025 \phi+0.015 \phi^{2}
$$

It was observed that the viscosity of the nanofluids increased considerably as the particle volume fraction increased; hence, increasing particle concentration had a direct influence on internal
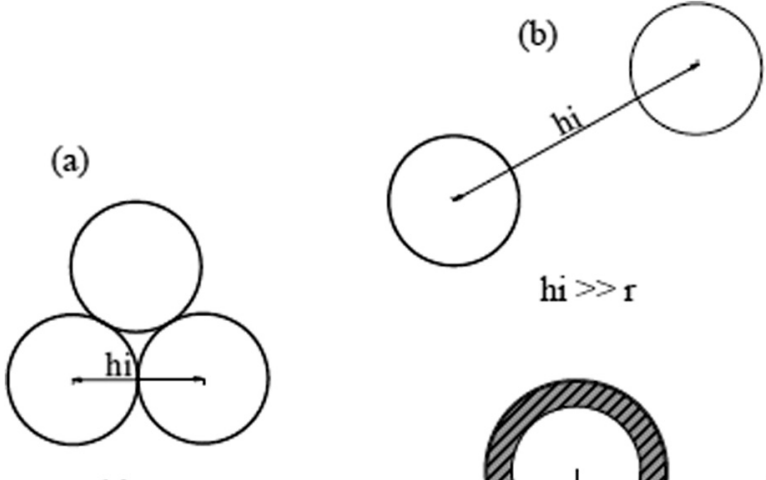

$\mathrm{hi}=2 \mathrm{r}$

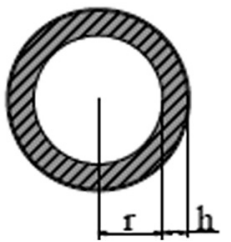

(c)

Fig. 2 Schematic of (a) closely packed nanoparticles, (b) loosely packed nanoparticles, and (c) and dimensions for a nanoparticle 
viscous shear stress. It was also observed that an increase in the fluid temperature had a weakening effect on the interparticle/intermolecule forces resulting in a decrease in the viscosity values. The viscosity-temperature gradient was seen to increase with higher volume fractions hence they concluded that the relative viscosity of the nanofluids $\eta_{\mathrm{r}}$ was based essentially on temperature and particle size. The following empirical models which are based on temperature were proposed for the nanofluids with nanoparticle sizes of $47 \mathrm{~nm}$ and $36 \mathrm{~nm}$, respectively [6]:

$$
\begin{gathered}
\eta_{\mathrm{r}}=1.125-0.007 T \\
\eta_{\mathrm{r}}=2.1275-0.0215 T+0.0002 T^{2}
\end{gathered}
$$

For higher volume fractions, however, it was not possible for them to provide a correlation that could simultaneously take into account temperature, particle concentration, and size effects on viscosity, hence the models are limited.

Avsec and Oblak [12] employed the concept of statistical nanomechanics in modeling the relative viscosity of nanofluids. They noted that the Cheng and Law [48] and Ward [12] models, which are expressed below, gave very good agreement for two-phase flow with particles larger than $100 \mathrm{~nm}$

$$
\begin{aligned}
\eta_{\mathrm{r}}=1+ & (2.5 \phi)+\left(\frac{35}{8}+\frac{5}{4} \beta\right) \phi^{2}+\left(\frac{105}{16}+\frac{35}{8}+\frac{5}{12} \beta^{2}\right) \phi^{3} \\
& +\left(\frac{1155}{128}+\frac{935}{96} \beta+\frac{235}{96} \beta^{2}+\frac{5}{48} \beta^{3}\right) \phi^{4} \ldots
\end{aligned}
$$

and

$$
\eta_{\mathrm{r}}=1+(2.5 \phi)+(2.5 \phi)^{2}+(2.5 \phi)^{3}+(2.5 \phi)^{4} \ldots
$$

where $\beta$ is the diffusion exponent. The foregoing equations were reported to be of little importance in nanoscale viscosity calculations since the nanoparticle size exceeds acceptable limits, this led to the following improved model known as the RW model [12]:

$$
\eta_{\mathrm{r}}=1+\left(2.5 \phi_{\mathrm{e}}\right)+\left(2.5 \phi_{\mathrm{e}}\right)^{2}+\left(2.5 \phi_{\mathrm{e}}\right)^{3}+\left(2.5 \phi_{\mathrm{e}}\right)^{4} \ldots
$$

where

$$
\phi_{\mathrm{e}}=\phi\left(1+\frac{h}{r}\right)^{3}
$$

where $\phi_{\mathrm{e}}$ is the effective volume fraction, $h$ is the thickness of the nanolayer, and $r$ is the particle radius. The critical hypothesis underlying the models is the liquid layering contribution. Notably, the following factors led to anomalous enhancement of viscosity [12]: motion of nanoparticles; molecular level of layering of the liquid at the liquid-particle interface; ballistic phenomena in nanoparticles; and clustering in nanoparticles. The work also compared the results of the Ward and RW models, and the experimental data for two different nanofluids: (i) $\mathrm{H}_{2} \mathrm{O} / \mathrm{TiO}_{2}$ (with a particle size of $27 \mathrm{~nm}$ ) and (ii) $\mathrm{H}_{2} \mathrm{O} / \mathrm{Al}_{2} \mathrm{O}_{3}$ (with a particle size of $13 \mathrm{~nm}$ ). The RW model was reported to agree nicely with the experimental results in predicting the relative viscosity. Conversely, the model does not incorporate all the parameters that lead to an anomalous enhancement in viscosity.

Hosseini and Ghader [14] employed the concept of local composition theory in modeling the viscosity of nanofluids. The local composition theory involves the expression of a fluid property in terms of local rather than overall composition when considered as a nonrandom mixture. Similarly, the nonrandom-two-liquid (NRTL) theory considers two reference fluids, and provides a useful point of departure for deriving semi-empirical equations to represent thermodynamic excess functions for nonideal mixtures. The NRTL can be used to correlate excess Gibb's free energy in terms of vapor-liquid or liquid equilibrium data. Hosseini and Ghader [14] obtained the following equations based on Eyring's viscosity $[49,50]$ and the NRTL models for a (two-fluid component) nanofluid:

$$
\begin{aligned}
& \xi=\operatorname{In}(\eta V)=\phi_{1} \phi_{2}\left(\frac{A_{21} G_{21}}{\phi_{1}+\phi_{2} G_{21}}+\frac{A_{12} G_{12}}{\phi_{2}+\phi_{1} G_{12}}\right)+\phi_{1} \xi_{1}+\phi_{2} \xi_{2} \\
& \text { where } A_{i j}=a_{i j}+b_{i j} T \text { and } G_{i j}=\exp \left(-\alpha A_{i j} / R T\right)
\end{aligned}
$$

For a three-component nanofluid, the following model was obtained [14]:

$$
\begin{aligned}
\xi= & \operatorname{In}(\eta V) \\
= & \phi_{1}\left(\frac{\phi_{2} G_{21}}{\phi_{1}+\phi_{2} G_{21}+\phi_{3} G_{31}} A_{21}+\frac{\phi_{3} G_{31}}{\phi_{1}+\phi_{2} G_{21}+\phi_{3} G_{31}} A_{31}\right) \\
& +\phi_{2}\left(\frac{\phi_{1} G_{12}}{\phi_{2}+\phi_{1} G_{12}+\phi_{3} G_{32}} A_{12}+\frac{\phi_{3} G_{32}}{\phi_{2}+\phi_{1} G_{12}+\phi_{3} G_{32}} A_{32}\right) \\
& +\phi_{3}\left(\frac{\phi_{1} G_{13}}{\phi_{2}+\phi_{1} G_{13}+\phi_{2} G_{23}} A_{13}+\frac{\phi_{2} G_{23}}{\phi_{3}+\phi_{1} G_{13}+\phi_{2} G_{23}} A_{23}\right) \\
& +\phi_{1} \xi_{1}+\phi_{2} \xi_{2}+\phi_{3} \xi_{3}
\end{aligned}
$$

The above models apparently require the knowledge of the effective viscosities of the constituent fluids in varying conditions for them to be useful. It is a complex model with fairly good accuracy (at least for results of $\mathrm{Al}_{2} \mathrm{O}_{3} / \mathrm{H}_{2} \mathrm{O}, \mathrm{CuO} / \mathrm{H}_{2} \mathrm{O}$ and $\mathrm{CuO} / \mathrm{EG}$, reported in the work). It seems, however, that the effects of agglomeration of nanoparticles at high temperature were not considered. The correlations obtained in the work may not be extended to multicomponent nanofluids as they require numerous parameters. More research is required to understand the effects of excess Gibb's free energy, pressure and temperature on nanofluid viscosity.

Abu-Nada [51] obtained a correlation for pure fluids, with respect to viscosity and temperature, given by

$$
\operatorname{In}\left(\frac{\eta_{\mathrm{nf}}}{\eta_{\mathrm{bf}}}\right) \approx a+b\left(\frac{T_{\mathrm{o}}}{T}\right)+c\left(\frac{T_{\mathrm{o}}}{T}\right)^{2}
$$

where $\eta_{\mathrm{bf}}$ and $T_{\mathrm{o}}$ are reference values. $a, b$, and $c$ are dimensionless curve-fitting constants. It was observed that fluids have higher viscosity values near their freezing point and reasonably low viscosity near their boiling temperature, indicating that viscosity is a strong function of temperature.

Masoud et al. [1] obtained a new dimensionless model for predicting the viscosity of nanofluids. The relative viscosity was determined from some dimensionless groups, which contain the following parameters: (i) viscosity of the base fluid, (ii) the hydrodynamic volume fraction of nanoparticles, (iii) diameter of a nanoparticle, and (iv) thickness of the capping layer. The following model was obtained [1]:

$$
\frac{\mu_{\mathrm{nf}}}{\mu_{\mathrm{bf}}}=\exp \left[m+\alpha\left(\frac{T}{T_{0}}\right)+\beta\left(\phi_{\mathrm{h}}\right)+\gamma\left(\frac{d}{1+r}\right)\right]
$$

where $\eta_{\mathrm{nf}}$ is the viscosity of the nanofluid, $\eta_{\mathrm{bf}}$ is the viscosity of the base fluid, $\phi_{\mathrm{h}}$ is the hydrodynamic volume fraction of solid nanoparticles, $d$ is a nanoparticle diameter, $r$ is the thickness of the capping layer, $T_{\mathrm{o}}$ is a reference temperature, and $T$ is the measured temperature. $\alpha, m$, and $\beta$ are empirical constants. Using the least-square regression method, the empirical constants for the model were calculated from a set of experimental data of $\mathrm{Al}_{2} \mathrm{O}_{3}$ / $\mathrm{H}_{2} \mathrm{O}$ water nanofluids (with $36 \mathrm{~nm}$ and $47 \mathrm{~nm}$ particle sizes). The obtained model results gave good agreement with the empirical data for plots of $\eta_{\mathrm{nf}} / \eta_{\mathrm{bf}}$ versus $T / T_{\mathrm{o}}$. There was also good agreement for plots of $\eta_{\mathrm{nf}} / \eta_{\mathrm{bf}}$ versus $\phi_{\mathrm{h}}$, the only exception being that 
other models which were used in the comparison (Einstein [37], Brinkman [45], and Batchelor [25]) were based on $\phi$ instead of $\phi_{\mathrm{h}}$. This could also have resulted in large differences in the model predictions. A reasonable plot would have been a plot of $\eta_{\mathrm{nf}} / \eta_{\mathrm{bf}}$ versus $\phi_{\mathrm{h}}$. The model results were limited to $\mathrm{Al}_{2} \mathrm{O}_{3} / \mathrm{H}_{2} \mathrm{O}$ nanofluids also.

Masoumi et al. [11] developed a new analytical model for calculating the viscosity of nanofluids. The critical assumption was that the relative velocity between the base fluid and nanoparticles was an important contribution hence underscoring the importance of the Brownian motion. The model obtained in the work was based on the following parameters: temperature, mean nanoparticle diameter, nanoparticle volume fraction, nanoparticle density, and base fluid thermophysical properties. A correction factor was incorporated into the model so as to account for simplifications of the applied boundary conditions on a volumetric element. The following relation for effective viscosity was given [11]:

$$
\eta_{\text {eff }}=\eta_{\mathrm{bf}}+\frac{\rho_{\mathrm{p}} V_{\mathrm{B}} d_{\mathrm{p}}^{2}}{72 C \delta}
$$

which have the following constraints:

$$
\begin{aligned}
& \phi<b / a, \text { and } \\
& b=c_{1} d_{p}+c_{2} \\
& a=c_{3} d_{p}+c_{4}
\end{aligned}
$$

where $\rho_{\mathrm{p}}$ is the particle density, $\delta$ is the distance between the centers of particles, $V_{\mathrm{B}}$ is the Brownian velocity, $C$ is the correction factor, and $d_{\mathrm{p}}$ is the particle diameter. The constant $C$ is defined by

$$
C=\eta_{\mathrm{bf}}^{-1}\left[\left(c_{1} d_{\mathrm{p}}+c_{2}\right) \phi+\left(c_{3} d_{\mathrm{p}}+c_{4}\right)\right]
$$

The Brownian velocity $V_{\mathrm{B}}$ is given by

$$
V_{\mathrm{B}}=\frac{1}{d_{\mathrm{p}}} \sqrt{\frac{18 K_{\mathrm{b}} T}{\pi \rho_{\mathrm{p}} d_{\mathrm{p}}}}
$$

$K_{\mathrm{b}}$ is the Boltzmann constant and $T$ is the temperature. The obtained results showed good agreement with a range of nanofluids: $\mathrm{CuO} / \mathrm{H}_{2} \mathrm{O}, \mathrm{CuO} / \mathrm{EG}, \mathrm{T}_{1} \mathrm{O}_{2} / \mathrm{EG}, \mathrm{CuO} / \mathrm{EG} / \mathrm{H}_{2} \mathrm{O}$, and $\mathrm{H}_{2} \mathrm{O} /$ $\mathrm{Al}_{2} \mathrm{O}_{3}$ in relation to varying temperatures, mean diameters, and volume fractions showing that the model can relatively account for the effects of those parameters. The steps required to evaluate the constants may limit its applicability, however.

To model the combined effects of shear rate and temperature on the apparent viscosity of $\mathrm{CuO} / \mathrm{H}_{2} \mathrm{O}$ and $\mathrm{CuO} / \mathrm{EG}$ nanofluids with 1.5 and $2.5 \%$ volume fractions of $\mathrm{CuO}$, Dzido et al. [2] applied the Klein's model

$$
\log (\eta)=A_{0}+A_{1} \log (\gamma)+A_{2} \log ^{2}(\gamma)+A_{3} T \log (\gamma)+A_{4} T+A_{5} T^{2}
$$

where $\eta$ is the apparent viscosity, $\gamma$ is the shear rate, and $A_{0} \ldots A_{5}$ are coefficients which were determined from the least square method. Plots of measured and calculated values of the effective viscosities gave good agreement, within $\pm 10 \%$ error margin. There model does not include the following relevant parameters, which include volume fraction, particle size and density.

Noni et al. [52] used the following model to predict the relative viscosity of $\mathrm{Al}_{2} \mathrm{O}_{3} / \mathrm{H}_{2} \mathrm{O}$ nanofluid:

$$
\mu_{\mathrm{r}}=1+b\left(\frac{\phi}{1-\phi}\right)^{n}
$$

where $b$ is an empirical parameter which is influenced by two factors; the first is related to electromagnetic effects and the second is related to mechanical-geometrical aspects of the particle, e.g., the specific surface area, density, and apparent sphericity. For the investigated nanofluid, the constant $b$ was fixed at 5300 by curvefitting, while the exponent $\eta$ was assigned the value, 2.8 . The consideration was that these values will reasonably account for the electromagnetic aspects of the nanoparticles due to increased surface area. The obtained results indicated that the error margin of the predicted and experimental values was within 3\% and $-15 \%$.

Brenner and Condiff [53] applied the following model in predicting the viscosity of dilute suspensions containing large aspect rodlike particles of EG/TNT nanofluids

$$
[\eta](\infty)=\frac{0.312 r}{\operatorname{In} 2 r-1.5}+2-\frac{0.5}{\operatorname{In} 2 r-1.5}-\frac{1.872}{r}
$$

where $[\eta]$ is the intrinsic viscosity and $r$ is the aspect ratio. However, the model underpredicted the measured data. The following empirical equation was then proposed from plots of high shear viscosity versus temperature reciprocals for the EG/TNT nanofluid [53]:

$$
\text { In } \eta=A+B \cdot \frac{1000}{T+C}
$$

Where $\eta$ is the shear viscosity and $T$ is the absolute temperature. $A, B$, and $C$ are empirical constants. The above is limited in that it contains only a temperature variable.

Namburu et al. [26] developed the following model to predict the viscosity of nanofluids composed of copper oxide nanoparticles suspended in 60:40 (on weight basis) of $\mathrm{EG} / \mathrm{H}_{2} \mathrm{O}$ mixtures:

$$
\log \left(\eta_{\mathrm{nf}}\right)=A e^{-B T}
$$

where $\eta_{\mathrm{nf}}$ is the effective viscosity of the copper oxide nanofluid, $T$ is the temperature of the nanofluid, $A$ and $B$ empirical constants, which are functions of the volumetric particle fraction $\phi$.

Kulkarni et al. [54] developed the following correlation for the viscosity of copper oxide nanoparticles suspended in water (with a temperature range of $5-50{ }^{\circ} \mathrm{C}$ ):

$$
\operatorname{In} \eta_{\mathrm{nf}}=A\left(\frac{1}{T}\right)-B
$$

The model, however, is limited to a narrow range of temperatures. The following model proposed by Kulkarni et al. [54] relates volume fraction and temperature to viscosity:

$$
\begin{aligned}
\text { In } \eta_{\text {eff }}= & -\left(2.8751+53.54 \phi-107.12 \phi^{2}\right) \\
& +\left(1078.3+15857 \phi+20587 \phi^{2}\right)(1 / T)
\end{aligned}
$$

Agglomeration of nanoparticles and some unexplained phenomena make the formulation of a generalized model a challenge, emphasizing the need to investigate the effects of the fundamental variables and parameters on the relative viscosity in order to determine the degree of conformity of the models with empirical data and more so predict the general trend of viscous performance the fluids in varying use conditions.

A summary of the relevant mathematical models is given in Table 1.

\section{Results and Discussion}

In Fig. 3, results of theoretical and empirical investigations are compared in consideration of nanoparticle diameter $d_{\mathrm{p}}$ and the relative viscosity $\eta_{\mathrm{r}}$. The results indicate decreasing relative viscosity values with increasing nanoparticle diameter values for the Graham [43] model while the contrary is the case for the RW [12] 
Table 1 Summary of nanofluid viscosity models

\begin{tabular}{|c|c|c|}
\hline Model & Expression & Description \\
\hline Einstein [37] & $\eta=\eta_{\mathrm{o}}(1+[\eta] \phi)$ & $\begin{array}{l}\text { Spherical particles and dilute suspension. } \\
\text { Typical intrinsic viscosity value: } 2.5 \text {. }\end{array}$ \\
\hline Krieger and Dougherty [4] & $\eta_{\mathrm{r}}=\eta / \eta_{\mathrm{o}}=\left(1-\phi / \phi_{\mathrm{m}}\right)^{-[\eta] \phi_{\mathrm{m}}}$ & $\begin{array}{l}\text { A broad range of concentration considered for } \\
\text { spherical particles. }\end{array}$ \\
\hline $\begin{array}{l}\text { Modified Krieger } \\
\text { and Dougherty [4] }\end{array}$ & $\eta_{\mathrm{r}}=\left(1-\varphi_{\mathrm{a}} / \varphi_{\mathrm{m}}\right)^{-[\eta] \varphi_{\mathrm{m}}}, \varphi_{\mathrm{a}}=\varphi\left(a_{\mathrm{a}} / a\right)^{3-D}$ & $\begin{array}{l}\text { Spherical particle with aggregation, considering } \\
\text { the radii of primary and aggregate particles. }\end{array}$ \\
\hline Frankel and Acrivos [42] & $\eta_{\mathrm{r}}=\frac{9}{8}\left[\frac{\left(\phi / \phi_{\mathrm{m}}\right)^{\frac{1}{3}}}{1-\left(\phi / \phi_{\mathrm{m}}\right)^{\frac{1}{3}}}\right]$ & $\begin{array}{l}\text { A broad range of concentration considered for } \\
\text { nanoparticles, in consideration of the maximum } \\
\text { packing fraction. }\end{array}$ \\
\hline Lundgren [46] & $\eta_{\mathrm{r}}=\left[1+2.5 \varphi+\frac{25}{4} \cdot \varphi^{2}+o\left(\varphi^{3}\right)\right]$ & $\begin{array}{l}\text { A broad range of concentration considered for } \\
\text { spherical particles. }\end{array}$ \\
\hline Batchelor [25] & $\eta / \eta_{\mathrm{o}}=1+[\eta] \phi+k_{\mathrm{H}}([\eta] \phi)^{2}$ & $\begin{array}{l}\text { Spherical particles and dilute suspension. With } \\
\text { Huggins's coefficient, } k_{\mathrm{H}} \text {, considered. }\end{array}$ \\
\hline Maiga et al. [59] & $\eta_{\mathrm{eff}}=\left(1-0.19 \phi+306 \phi^{2}\right) \mu_{\mathrm{b}}$ & $\begin{array}{l}\text { Obtained in consideration of volumetric } \\
\text { fractions, and also narrowly considers other } \\
\text { parameters. }\end{array}$ \\
\hline Ward [12] & $\eta_{\mathrm{r}}=1+(2.5 \alpha)+(2.5 \alpha)^{2}+(2.5 \alpha)^{3}+(2.5 \alpha)^{4} \ldots$ & $\begin{array}{l}\text { Obtained on the basis of statistical } \\
\text { nanomechanics. }\end{array}$ \\
\hline RW [12] & $\begin{aligned} \eta_{\mathrm{r}} & =1+\left(2.5 \alpha_{\mathrm{e}}\right)+\left(2.5 \alpha_{\mathrm{e}}\right)^{2}+\left(2.5 \alpha_{\mathrm{e}}\right)^{3} \\
& +\left(2.5 \alpha_{\mathrm{e}}\right)^{4} \cdots, \alpha_{\mathrm{e}}=\alpha\left(1+\frac{h}{r}\right)^{3}\end{aligned}$ & $\begin{array}{l}\text { Obtained on the basis of statistical- } \\
\text { nanomechanics; includes thickness of the liquid } \\
\text { layer and the aspect ratio. }\end{array}$ \\
\hline Masoumi et al. [11] & $\eta_{\mathrm{eff}}=\eta_{\mathrm{bf}}+\frac{\rho_{\mathrm{P}} V_{\mathrm{B}} d_{\mathrm{P}}^{2}}{72 C \delta}$ & $\begin{array}{l}\text { Considers the relative velocity between the base } \\
\text { fluid and nanoparticles, and a broad range of } \\
\text { parameters. }\end{array}$ \\
\hline Hosseini et al [1] & $\frac{\eta_{\mathrm{nf}}}{\eta_{\mathrm{bf}}}=\exp \left[m+\alpha\left(\frac{T}{T_{0}}\right)+\beta\left(\phi_{\mathrm{h}}\right)+\gamma\left(\frac{d}{1+r}\right)\right]$ & $\begin{array}{l}\text { Based on dimensionless groups considers a } \\
\text { broad range of parameters. }\end{array}$ \\
\hline Hosseini et al. [1] & $\xi=\operatorname{In}(\mu V)=\phi_{1} \phi_{2}\left(\frac{A_{21} G_{21}}{\phi_{1}+\phi_{1} G_{21}}+\frac{A_{12} G_{12}}{\phi_{2}+\phi_{1} G_{12}}\right)+\phi_{1} \xi_{1}+\phi_{2} \xi_{2}$ & Based on Eyring's viscosity and NRTL models. \\
\hline
\end{tabular}

model, in which the relative viscosity increases with nanoparticle diameter. Data from the experimental work of Lu and Fan [55], and Kwek et al. [56] indicate a drop in the value of $\eta_{\mathrm{r}}$ with increasing $d_{\mathrm{p}}$ values. The disparity in the model predictions and the empirical data emphasizes the need to employ functional mechanisms in modeling the viscosity. Only two of the reported

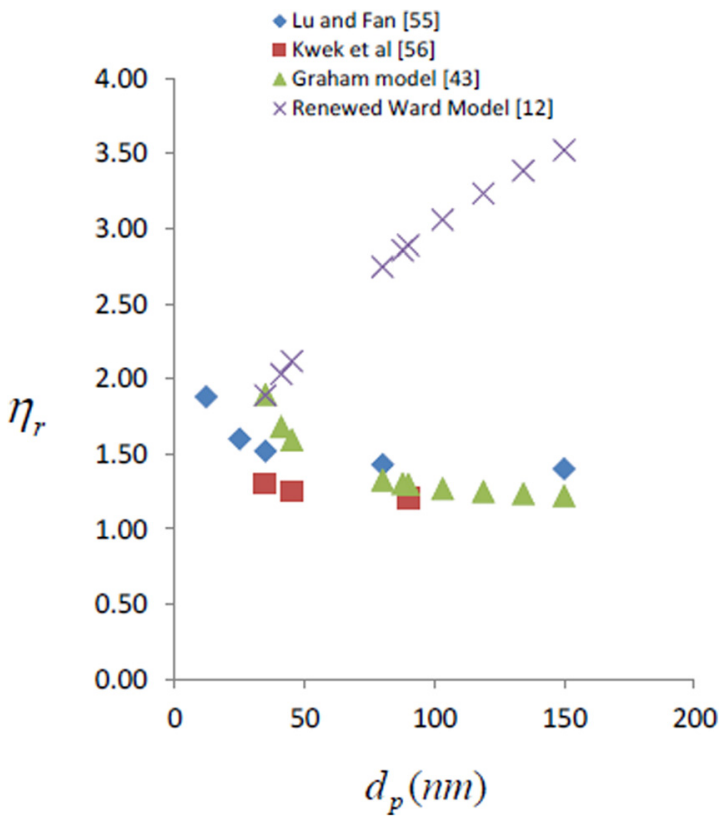

Fig. 3 Comparison of empirical data with the model predictions for $\eta_{\mathrm{r}}$ versus $d_{\mathrm{p}}$ models include the effects of particle diameter on the relative viscosity.

In Fig. 4, the prediction of the model proposed by Kulkarni et al. [54] is compared with the empirical data of Nguyen et al. [2] for $\mathrm{CuO} / \mathrm{H}_{2} \mathrm{O}$ nanofluids. From the results, the trends of the model predictions show a good correspondence; however, there is a wide margin between the model predictions and the empirical data. Notably, the model by Kulkarni et al. [54] incorporates $\phi$ and $T$ as

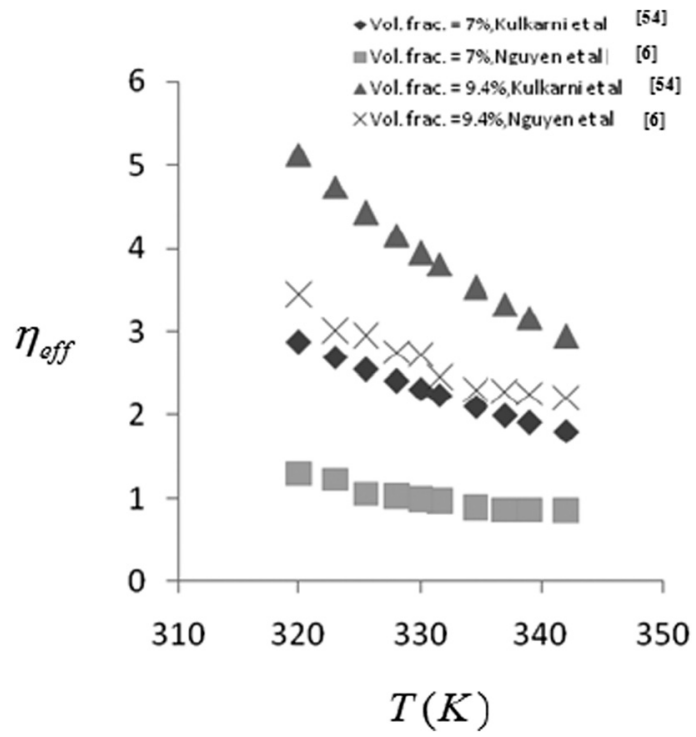

Fig. 4 Comparison of empirical data with the model predictions for $\eta_{\text {eff }}$ versus $T$ 


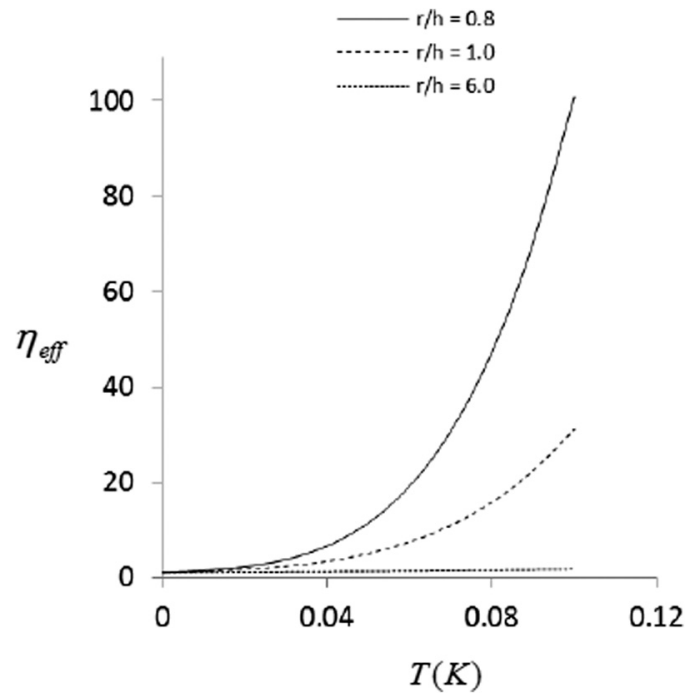

Fig. 5 Evolution of $\eta_{\mathrm{r}}$ with $r / h$ for the RW model [12]

independent variables. With this model, there is prospect for improved prediction of nanofluid viscosity data. One possible way of correcting this model is to compare its results with a range of nanofluid viscosity data, and then an improvement could be to incorporate a correction factor. In Fig. 5, the effects of increasing values of $r / h$ parameter are investigated. The ratio gives the relative change in $\eta_{\mathrm{r}}$ with respect to the thickness of the nanolayer. When $r / h<1, \eta_{\mathrm{r}}$ increases considerably with $\phi$. And when $r / h \geq 1$, the increase in the relative viscosity values becomes less dependent on $\phi$. In a limiting case, $\eta_{\mathrm{r}}$ becomes a constant with increasing $\phi$ values; however, this is hardly feasible at the nanoscale.

The evolution of the relative viscosity values with $\phi / \phi_{\mathrm{m}}$ is plotted in Fig. 6. The modified K-D model predicts the increase in $\eta_{r}$ reasonably than the other models. The trend of $\eta_{\mathrm{r}}$ versus $\phi / \phi_{m}$ plots is somewhat consistent with empirical works [14-17]. The ratio hardly exceeds 0.6 in practical conditions. The modified $\mathrm{K}-\mathrm{D}$ model [8] gives higher values of $\eta_{r}$ compared to the K-D [4] and Frankel and Acrivos [42] models. The model by Krieger and Dougherty [4] shows a linear relationship between $\eta_{\mathrm{r}}$ and $\phi / \phi_{\mathrm{m}}$ while the other models show a nonlinear relationship owing to their forms.

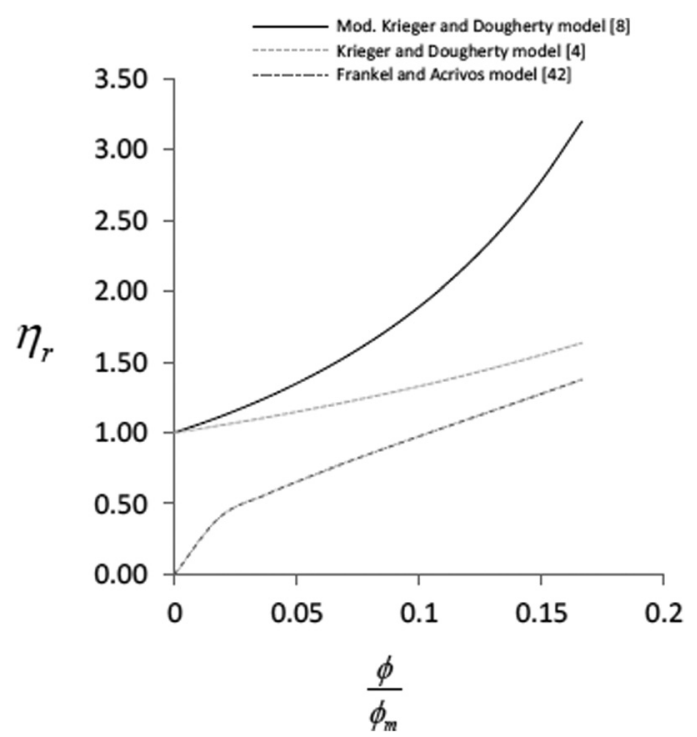

Fig. 6 Effects of increasing $\phi / \phi_{\mathrm{m}}$ values on $\eta_{\mathrm{r}}$

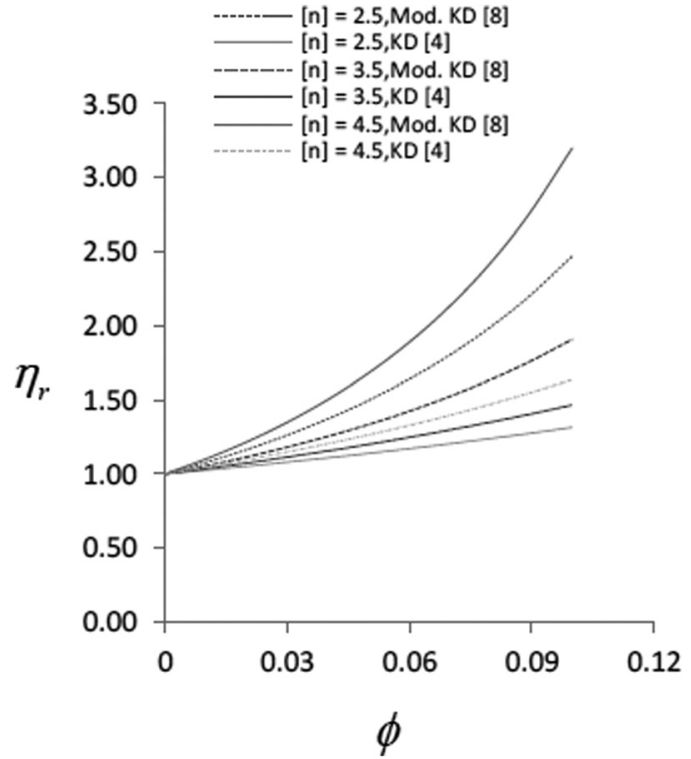

Fig. 7 Evolution of $\eta_{\mathrm{r}}$ with $\phi$ for the modified K-D [8] and K-D models [4]

In Fig. 7, the effects of the intrinsic viscosity $[\eta]$ and the volumetric fraction are plotted. $[\eta]$ gives the solute contribution to the viscosity of a nanofluid. Higher $[\eta]$ values suggest increasing solute effects, the higher the solute contribution the higher viscosity values. The intrinsic viscosity increases the solute (base fluid) viscosity since it is coupled to the size and shape of nanoparticles. It is most likely that entanglement of nanoparticles will result in an increase in the intrinsic viscosity values, which possibly will lead to an increase in the relative viscosity of nanofluids. Studies on the effects of nanoparticle size, size distribution, and shape on the intrinsic viscosity as affected by base fluid density, polarity, and temperature are limited. Einstein [37] proposed an intrinsic viscosity value of 2.5. However, the results of Anoop et al. [38] show that the intrinsic viscosity can get to 10.0. Further investigation is consequently needed to understand the solute contribution to viscosity of nanofluids.

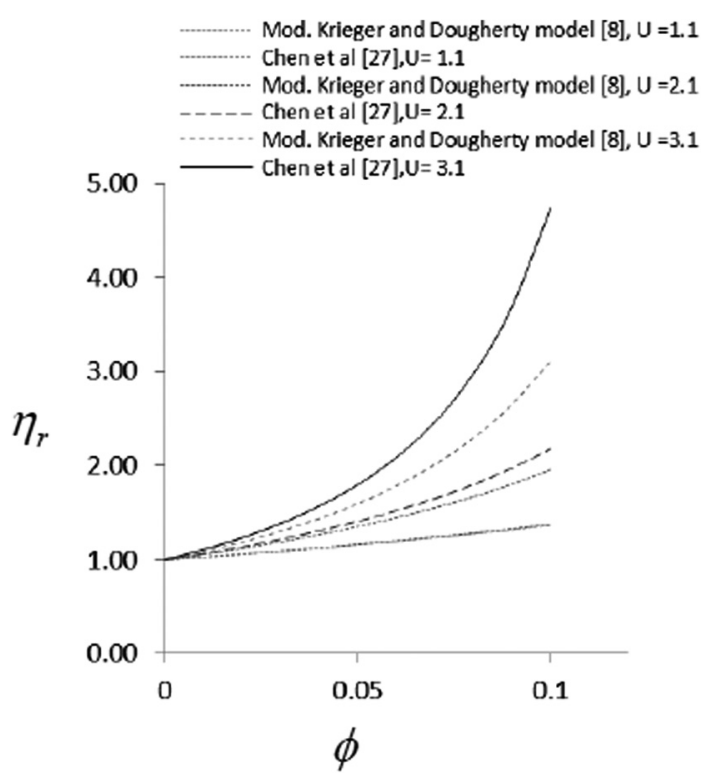

Fig. 8 Evolution of $\eta_{\mathrm{r}}$ with $\phi$ for the modified K-D [8] and Chen et al. [27] models 


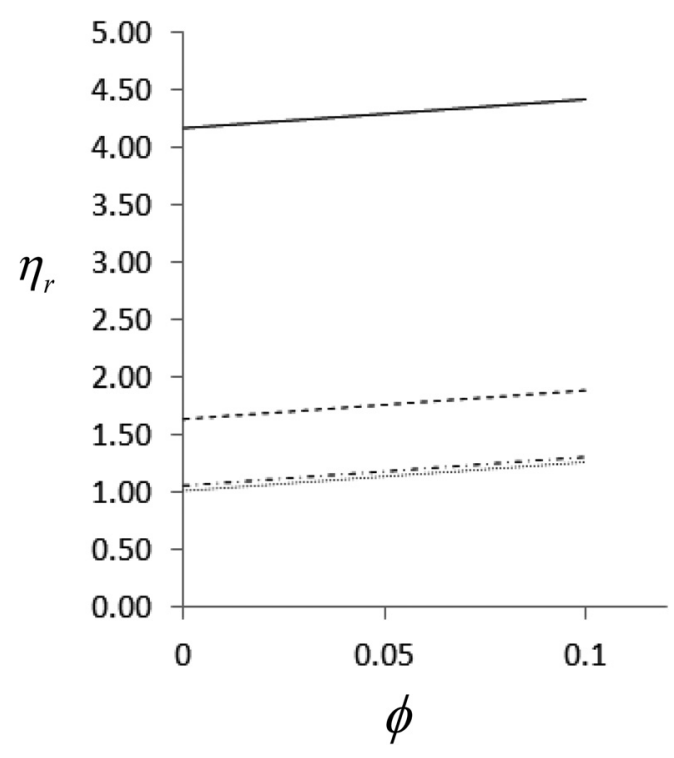

Fig. 9 Evolution of $\eta_{\mathrm{r}}$ with $\phi$ for the modified K-D [8] and K-D models [4]

In Fig. 8, parameter $U$ is expressed as $U=a_{\mathrm{a}} / a$. Results of variation of this parameter are compared for the modified K-D [8] and Chen et al. [27] models. As the parameter varies from 1.1 to 3.1, obvious differences are seen in predicted values. At $U=1.1$, the values predicted by the modified Krieger and Dougherty [8] and Chen et al. [27] models are identical, however, as $U$ increases to 3.1 , significant differences are noticeable in their predictions. The reason for this could be as a result of the forms of the equa-tions. Markedly, as $U$ increases the prediction of the Chen et al.[27] further deviates from that of the modified K-D [8].

Figure 9 shows the effects of the ratio $h_{i} / d_{\mathrm{p}}$ on the relative viscosity for the Graham model [43]. As the volume fraction increases from 0 to 0.1 , the maximum values of the relative vis-cosity is obtained at the value of $h_{i} / d_{\mathrm{p}}=0.1$. It is seen that decreasing values of $h_{i} / d$ affects the relative viscosity values. Increasing $h_{i} / d_{\mathrm{p}}$ values give an indication of growing nanoparticle agglomeration in a nanofluid. This has been reported to be one of the factors leading to anomalous increase in the relative viscosity [6-8]; hence, the obtained results underpin the hypothesis that says that increased agglomeration could be due to an increase in the volumetric fraction which in turn could lead to low $h_{i} / d_{\mathrm{p}}$ val-ues. There is, however, a basis for further research investigations to thoroughly understand the effects [57-59].

\section{Conclusion}

The concept of a generalized model in nanofluidic systems is of important benefit as such this study examined the effects of viscosity parameters on the viscous behavior of nanofluids which have a wide range of potential applications, considering some theoretical and empirical results. It was found that the predictions of the models were at variance with the empirical data. Notably, in some cases, the theoretical predictions showed a nonlinear relationship between the relative viscosity and the fundamental variables. Also, the disparity in the model predictions reveals that the models mostly incorporate parameters which do not or are inadequate to account for some of the observed phenomena in nanofluids, particularly hysteresis and the effects of dispersion energy on aggregation and re-aggregation. Overall, future investigations should place emphasis on models which are sufficiently generalized, and take into consideration the following: aggregation (or flocculation), particle or aggregate size distribution, particle and aggregate shapes, solvent quality, density, effects of stabil-izers, and surfactants as well as base fluid polarity, so as to

\section{Acknowledgment}

The funding for this project was provided by University of Preto-ria, South Africa, as part of a postdoctoral research grant. The sup-port of management and research staff of the Department of Mechanical and Aeronautical Engineering is kindly acknowledged.

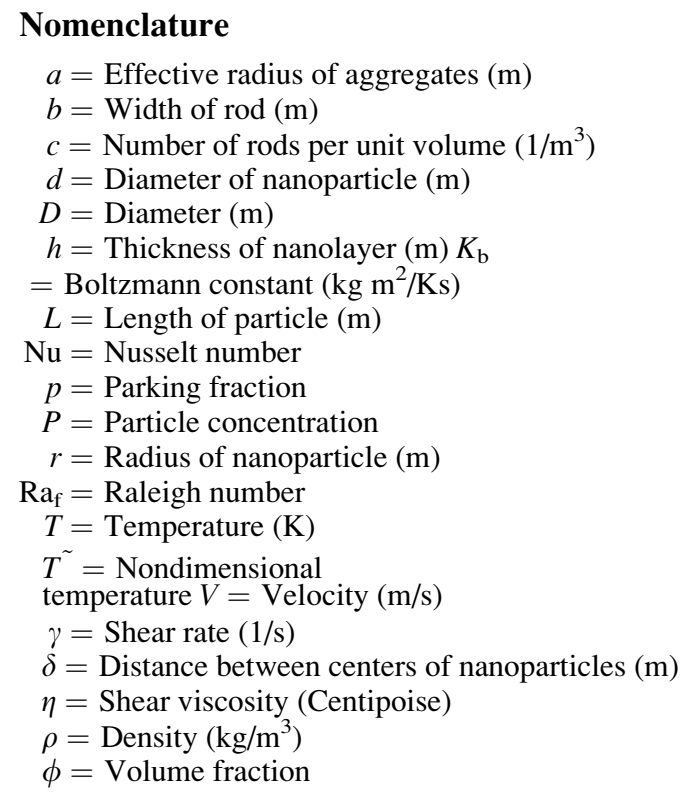

\section{Subscripts}

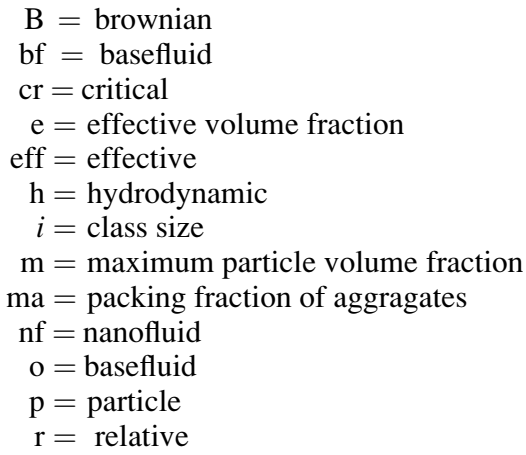

\section{References}

[1] Hosseini, S. M., Moghadassi, A. R., and Henneke, D. E., 2010, "A New Dimensionless Group Model for Determining the Viscosity of Nanofluids," J. Therm. Anal. Calorim., 100(3), pp. 873-877.

[2] Dzido, G., Chmiel-Kurowska, K., Gierczycki, A., and Jarze,bski, A. B.,

2009 Application of Klein's Equation for Description of Viscosity of Nanofluid," Comput. Aided Chem. Eng., 26, pp. 955-960.

[3] Ho, C. J., Chen, M. W., and Li, Z. W., 2008, "Numerical Simulation of Natural Convection of Nanofluid in a Square Enclosure: Effects Due to Uncertainties of Viscosity and Thermal Conductivity," Int. J. Heat Mass Transfer, 51(17-18), pp. $4506-4516$.

[4] Krieger, I. M., and Dougherty, T. J., 1959, "A Mechanism for Non-Newtonian Flow in Suspensions of Rigid Spheres,” Trans. Soc. Rheol., 3(1), pp. 137-152.

[5] Keblinski, P., Phillpot, S. R. E., Choi, S. U. S., and Eastman, J. A., 2002, "Mechanisms of Heat Flow in Suspensions of Nano-Sized Particles (Nanofluids)," Int. J. Heat Mass Transfer, 45(4), pp. 855-863.

[6] Nguyen, C. T., Desgranges, F., Roy, G., Galanis, N., Mar'e, T., Boucher, S., and Mintsa, H. A., 2007, "Temperature and Particle-Size Dependent Viscosity Data for Water-Based Nanofluids-Hysteresis Phenomenon," Int. J. Heat Fluid Flow, 28(6), pp. 1492-1506.

[7] Choi, S. U. S., and Eastman, J. A., 1995, "Enhancing Thermal Conductivity of Fluid With Nanoparticles," International Mechanical Engineering Congress and Exhibition, San Francisco, CA, Nov. 12-17.

[8] Wang, L. Q., ed., 2009, Advances in Transport Phenomena, ADVTRANS 1, Springer-Verlag, Berlin, Heidelberg, Germany, pp. 135-177. 
[9] Venerus, D. C., Buongiorno, J., Christianson, R., Townsend, J., Bang, I. C., Chen, G., Chung, S. J., Chyu, M., Chen, H., Ding, Y., Dubois, F., Dzido, G., Funfschilling, D., Galand, Q., Gao., J., Hong, H., Horton, M., Hu, L., Iorio, C. S., Jarzebski, A. B., Jiang., Y., Kabelac, S., Mark, K. A., Kim, C., Kim, J., Kim, S., McKrell, T., Ni, R., Philip, J., Prabhat, N., Song, P., Vaerenbergh, S. V., Wen, D., Witharana, S., Zhao, X., and Zhou, S., 2010, "Viscosity Measurements," Appl. Rheol., 20(4), pp. 1-7.

[10] Yanjiao, L., Zhou, J., Tung, S., Schneider, E., and Xi, S., 2009, “A Review on Development of Nanofluid Preparation and Characterization," Powder Technol., 196(2), pp. 89-101.

[11] Masoumi, N., Sohrabi, N., and Behzadmehr, A., 2009, "A New Model for Calculating the Effective Viscosity of Nanofluids," J. Phys. D: Appl. Phys., 42(5), p. 055501.

[12] Avsec, J., and Oblak, M., 2007, "The Calculation of Thermal Conductivity, Viscosity and Thermodynamic Properties for Nanofluids on the Basis of Statistical Nanomechanics,” Int. J. Heat Mass Transfer, 50(21-22), pp. 4331-4341.

[13] Okhio, C., Hodges, D., and Black, J., 2010, "Review of Literature on Nanofluid,” Multidiscip. J. Sci. Technol., J. Sel. Areas Nanotechnol. (JSAN), pp. 1-8.

[14] Hosseini, M., and Ghader, S., 2010, "A Model for Temperature and Particle Volume Fraction Effect on Nanofluid Viscosity,” J. Mol. Liq., 153(2-3), pp. 139-145.

[15] Chen, H., Ding, Y., Lapkin, A., and Fan, X., 2009, "Rheological Behaviour of Ethylene Glycol-Titanate Nanotube Nanofluids,” J. Nanopart. Res., 11(6), pp. $1513-1520$.

[16] Renon, H., and Prausnitz, J. M., 1968, "Local Composition in Thermodynamics Excess Functions for Liquid Mixtures," J. AIChE, 14(1), pp. 135-144.

[17] Schmidt, A. J., Chiesa, M., Torchinsky, D. H., Jeremy, A., Boustani, A., McKinley, G. H., Nelson, K. A., and Johnson, G. C., 2008, "Experimenta Investigation of Nanofluid Shear and Longitudinal Viscosities," Appl. Phys. Lett. $92(24)$, p. 244107.

[18] Wong, K. V., and Leon, O., 2010, "Applications of Nanofluids: Current and Future,” Adv. Mech. Eng., 5, p. 519659.

[19] V'ek'as, L., Marinic ‘a, O., Susan-Resiga, D., Stoian, F. D., and Bica, D., 2004, "Magnetic and Flow Properties of High Magnetization Nanofluids," Proceedings of the 6th International Conference on Hydraulic Machinery and Hydrodynamics, Timisoara, Romania, Oct. 21-22.

[20] Yu, W., Xie, H., Li, Y., and Chen, L., 2011, "Experimental Investigation on Thermal Conductivity and Viscosity of Aluminum Nitride Nanofluid," Particuology, 9(2), pp. 187-191.

[21] Prasher, R., Song, D., Wang, J., and Phelan, P. E., 2006, "Measurements of Nanofluid Viscosity and Its Implications for Thermal Applications," Appl. Phys. Lett., 89(13), p. 133108.

[22] Pastoriza-Gallego, M. J., Casanova, C., Legidoa, J. L., and Pi neiro, M. M., 2011, "CuO in Water Nanofluid: Influence of Particle Size and Polydispersity on Volumetric Behaviour and Viscosity," Fluid Phase Equilib., 300(1-2), pp. 188196.

[23] Garg, J., Poudel, B., Chiesa, M., Gordon, J. B., Ma, J. J., Wang, J. B., Ren, Z. F., Kang, W. T., Ohtani, H., Nanda, J., McKinley, G. H., and Chen, G., 2008 , "Enhanced Thermal Conductivity and Viscosity of Copper Nanoparticles in Ethylene Glycol Nanofluid," J. Appl. Phys., 103(7), p. 074301.

[24] Tavman, I., Turgut, A., Chirtoc, M., Schuchmann, H. P., and Tavman, S., 2008, "Experimental Investigation of Viscosity and Thermal Conductivity of Suspensions Containing Nanosized Ceramic Particles," Arch. Mater. Sci. Eng., 34(2), pp. $99-104$

[25] Batchelor, G. K., 1977, "The Effect of Brownian Motion on the Bulk Stress in a Suspension of Spherical Particles," J. Fluid Mech., 83(1), pp. 97-117.

[26] Namburu, P. K., Kulkarni, D. P., Misra, D., and Das, D. K., 2007, "Viscosity of Copper Oxide Nanoparticles Dispersed in Ethylene Glycol and Water Mixture," Exp. Therm. Fluid Sci., 32(2), pp. 397-402.

[27] Chen, H., Ding, Y., and Tan, C., 2007, "Rheological Behaviour of Nanofluids," New J. Phys., 9, p. 367.

[28] Zhou, S., Ni, R., and Funfschilling, D., 2010, "Effects of Shear Rate and Temperature on Viscosity of Alumina Polyalphaolefins Nanofluids," J. Appl. Phys., 107(5), p. 054317.

[29] Tammann, G., and Hesse, W., 1926, "Die Abh"angigkeit der Viscosit" at von

der Temperatur bie unterk" uhlten Fl "ussigkeiten," Z. Anorg. Allg. Chem., 156(1), pp. 245-247.

[30] Paul, C. W., and Cotts, P. M., 1986, "Effects of Aggregation and Solvent Quality on the Viscosity of Semidilute Poly(vinylbutyra1) Solutions," Macromolecules, 19(3), pp. 692-699.

[31] Chandrasekar, M., Suresh, S., and Chandra, B. A., 2010, "Experimental Investigations and Theoretical Determination of Thermal Conductivity and Viscosity of $\mathrm{Al}_{2} \mathrm{O}_{3}$ /Water Nanofluid," Exp. Therm. Fluid Sci., 34(2), pp. 210-216.
[32] Murshed, S. M. S., Leong, K. C., and Yang, C., 2008, "Investigations of Thermal Conductivity and Viscosity of Nanofluids,” Int. J. Therm. Sci., 47(5), pp. 560-568.

[33] Tsai, T., Kuo, L., Chen, P., and Yang, C., 2008 "Effect of Viscosity of

Base Fluid on Thermal Conductivity of Nanofluids," Appl. Phys. Lett., 93(23), p. 233121.

[34] He, Y., Jin, Y., Chen, H., Ding, Y., Cang, D., and Lu, H., 2007, "Heat Transfer and Flow Behaviour of Aqueous Suspensions of $\mathrm{TiO}_{2}$ Nanoparticles (Nanofluids) Flowing Upward Through a Vertical Pipe," Int. J. Heat Mass Transfer, 50(11-12), pp. 2272-2281.

[35] Putnam, P. A., Cahill, D. G., Braun, P. V., Ge, Z., and Shimmin, R. G., 2006, "Thermal Conductivity of Nanoparticle Suspensions," J. Appl. Phys., 99(8), p. 084308.

[36] Xie, H., Chen, L., and Wu, Q., 2008, "Measurements of the Viscosity of Suspensions (Nanofluids) Containing Nanosized $\mathrm{Al}_{2} \mathrm{O}_{3}$ Particles," High Temp.High Pressure, 37(2), pp. 127-135.

[37] Einstein, A., 1906, "Eineneuebestimmung der molekuldimensionen," Ann. Phys. 324(2), pp. 289-306.

[38] Anoop, K. B., Kabelac, S., Sundararajan, T., and Das, S. K., 2009, "Rheological and Flow Characteristics of Nanofluids: Influence of Electroviscous Effects and Particle Agglomeration," J. Appl. Phys., 106(3), p. 034909.

[39] Farris, R. D., 1968, "Prediction of the Viscosity of Multimodal Suspensions From Unimodal Viscosity Data," Trans. Soc. Rheol., 12(2), p. 281.

[40] Muralidharan, G., and Runkana, V., 2009, "Rheological Modeling of Spherical Polymeric Gels and Dispersions Incorporating the Influence of Particle Size Distribution and Surface Forces," Ind. Eng. Chem. Res., 48(19), pp. 8805-8811.

[41] Larson, R. G., 1999, The Structure and Rheology of Complex Fluids, Oxford University, Oxford, UK.

[42] Frankel, N. A., and Acrivos, A., 1967, "On the Viscosity of a Concentrated Suspension of Solid Spheres," Chem. Eng. Sci, 22(6), pp. 847-853.

[43] Graham, A. L., 1981, "On the Viscosity of Suspension of Solid Spheres," Appl. Sci. Res., 37(3-4), pp. 275-286.

[44] Servais, C., Jones, R., and Roberts, I., 2002, "The Influence of Particle Size Distribution on the Processing of Food," J. Food Eng., 51(3), pp. 201-208.

[45] Brinkman, H. C., 1952, "The Viscosity of Concentrated Suspensions and Solution," J. Chem. Phys., 20(4), pp. 571-581.

[46] Lundgren, T. S., 1972, "Slow Flow Through Stationary Random Beds and Suspensions of Spheres," J. Fluid Mech., 51(2), pp. 273-299.

[47] Doi, M., and Edwards, S. F., 1978, "Dynamics of Rod-like Macromolecules in Concentrated Solution," J. Chem. Soc., Faraday Trans., Part 2, 2(74), pp. 918-932.

[48] Cheng, N.-S., and Law, A. W.-K., 2003, "Exponential Formula for Computing Effective Viscosity," Powder Technol., 129(1-3), pp. 156-160.

[49] Powell, R. E., Roseveare, W. E., and Henry, E., 1941, "Diffusion, Thermal Conductivity, and Viscous Flow of Liquids," Ind. Eng. Chem., 33(4), pp. 430-435.

[50] Renon, H., and Prausnitz, J. M., 1968, "Local Composition in Thermodynamics Excess Functions for Liquid Mixtures," AIChE J., 14(1), pp. $135-144$

[51] Abu-Nada, E., 2009, "Effects of Variable Viscosity and Thermal Conductivity of Al2O3-Water Nanofluid on Heat Transfer Enhancement in Natural Convection,” Int. J. Heat Fluid Flow, 30(4), pp. 679-690.

[52] Noni, A., Garcia, D. E., and Hotza, D., 2002, "A Modified Model for the Viscosity of Ceramic Suspensions," Ceram. Int., 28(7), pp. 731-735.

[53] Brenner, H., and Condiff, D. W., 1974, "Transport Mechanics in Systems of Orientable Particles. IV. Convective Transport,” J. Colloid Interface Sci., 47(1), pp. 199-264.

[54] Kulkarni, D. P., Das, D. K., and Chukwu, G. A., 2006, "Temperature Dependent Rheological Property of Copper Oxide Nanoparticles Suspension," J. Nanosci. Nanotechnol., 6(4), pp. 1150-1154.

[55] Lu, W. Q., and Fan, Q. M., 2008, "Study for the Particle's Scale Effect on Some Thermophysical Properties of Nanofluids by a Simplified Molecular Dynamics Method,” Eng. Anal. Boundary Elem., 32(4), pp. 282-289.

[56] Kwek, D., Crivoi, A., and Duan, F., 2010, "Effects of Temperature and Particle Size on the Thermal Property Measurements of $\mathrm{Al}_{2} \mathrm{O}_{3}$-Water Nanofluids," J. Chem. Eng. Data, 55(12), pp. 5690-5695.

[57] Doi, M., and Edwards, S. F., 1978, "Dynamics of Rod-Like Macromolecules in Concentrated Solution," J. Chem. Soc., Faraday Trans., Part 1, 2(74) pp. 560-570.

[58] White, F. M., 1991, Viscous Fluid Flow, McGraw-Hill, New York.

[59] Maiga, S. E. B., Nguyen, C. T., Galanis, N., and Roy, G., 2004, "Heat Transfer Behaviours of Nanofluids in a Uniformly Heated Tube," Superlattices Microstruct., 35(3-6), pp. 543-557. 